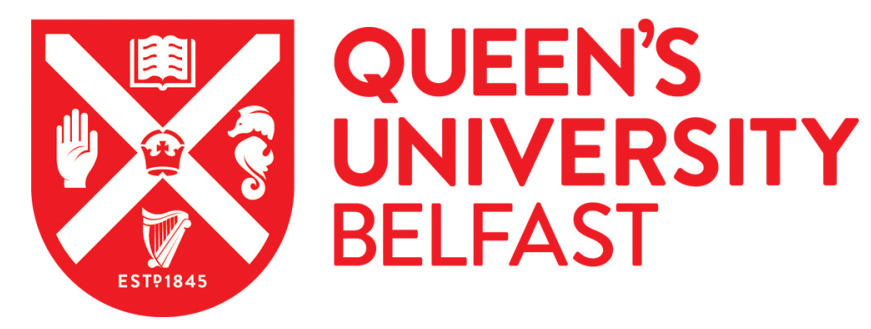

\title{
Periodate - an alternative oxidant for testing potential water oxidation catalysts
}

Mills, A., Hazafy, D., Elouali, S., \& O'Rourke, C. (2016). Periodate - an alternative oxidant for testing potential water oxidation catalysts. Journal of Materials Chemistry A, 4(8), 2863-2872.

https://doi.org/10.1039/C5TA06510K

\section{Published in:}

Journal of Materials Chemistry A

\section{Document Version:}

Peer reviewed version

Queen's University Belfast - Research Portal:

Link to publication record in Queen's University Belfast Research Portal

\section{Publisher rights}

C The Royal Society of Chemistry 2016

\section{General rights}

Copyright for the publications made accessible via the Queen's University Belfast Research Portal is retained by the author(s) and / or other copyright owners and it is a condition of accessing these publications that users recognise and abide by the legal requirements associated with these rights.

Take down policy

The Research Portal is Queen's institutional repository that provides access to Queen's research output. Every effort has been made to ensure that content in the Research Portal does not infringe any person's rights, or applicable UK laws. If you discover content in the Research Portal that you believe breaches copyright or violates any law, please contact openaccess@qub.ac.uk. 


\title{
Periodate - an alternative oxidant for testing potential water oxidation catalysts
}

\author{
Andrew Mills, David Hazafy, Sofia Elouali and Christopher O'Rourke \\ School of Chemistry and Chemical Engineering, Queen's University Belfast, David \\ Keir Building, Stranmillis Road, Belfast, BT9 5AG, UK \\ e-mail: andrew.mills@qub.ac.uk
}

\begin{abstract}
The redox catalyst ruthenium dioxide, prepared via the Adams technique, i.e. $\mathrm{Ru}$ (Adams), is used as a water oxidation catalyst using the oxidants (i) $\mathrm{Ce}$ (IV) in 0.5 $\mathrm{M} \mathrm{H}_{2} \mathrm{SO}_{4}$ and (ii) periodate in $0.5 \mathrm{M} \mathrm{H}_{2} \mathrm{SO}_{4}$, water and $0.1 \mathrm{M} \mathrm{KOH}$. Like Ce(IV), periodate is a very strong oxidant that is able to oxidise water to oxygen and can be readily monitored spectrophotometrically at $280 \mathrm{~nm}$, compared with $430 \mathrm{~nm}$ for Ce(IV). More importantly, unlike Ce(IV), which is unstable towards hydrolysis above $\mathrm{pH} 1$, periodate is stable in acid, water and strong alkali. A spectrophotometric study of the kinetics of periodate reduction, and concomitant oxidation of water to $\mathrm{O}_{2}$, reveals that in the presence of a suitable redox catalyst, Ru(Adams) in this work, periodate is able to effect the stoichiometric oxidation of water, with a turnover number $>64$. In just water, the kinetics of the latter reaction appear diffusion-controlled, due to the large thermodynamic driving force, a measure of which is the difference in redox potential, i.e. $\Delta \mathrm{E}=423 \mathrm{mV}$. As this difference is decreased, $\Delta \mathrm{E}=396 \mathrm{mV}$ in acid and $290 \mathrm{mV}$ in strong alkali $(0.1 \mathrm{M} \mathrm{KOH})$, the kinetics become increasingly activation-controlled and slower. These findings are discussed briefly with regard to the possible use of (i) periodate as an alternative oxidant in the rapid screening of new potential water oxidation catalyst material powders that are stable only under near neutral and/or alkaline conditions, and (ii) Ru(Adams) as a benchmark catalyst.
\end{abstract}

Keywords: Oxygen-catalysis, periodate, ruthenium dioxide, redox catalysis, Adams catalyst

\section{Introduction}


There has been much renewed interest in recent years in the development of efficient, long-lived, low-cost, solar-driven photosystems for the splitting of water into hydrogen and oxygen ${ }^{1-3}$. One of the great challenges in creating such a system is the identification of a suitable redox catalyst to mediate the oxidation of water, the oxygen evolution reaction, OER, by the photogenerated oxidant, which is usually a photogenerated valance-band hole in a semiconductor photocatalyst ${ }^{4,5}$. The reason for the significant interest in water oxidation catalysts, WOCs, rather than water reduction catalysts is that the oxidation of water is an electrochemically irreversible process, i.e. has a very low exchange current density, typically $<10^{-5} \mathrm{~mA} \mathrm{~cm}{ }^{-2}$, whereas water reduction is normally an electrochemically reversible process with a high exchange current density on many materials ${ }^{4}$, i.e. typically $>0.1 \mathrm{~mA} \mathrm{~cm}^{-2}$. Thus, even when using the most active electrocatalysts, it follows that a much greater overpotential is required to drive the former (ca. $256 \mathrm{mV}$ using $\mathrm{RuO}_{2}$ ) than the latter (ca. $25 \mathrm{mV}$ using $\mathrm{Pt})$ at a current density $(20 \mathrm{~mA} \mathrm{~cm})^{-2}$ that is typically associated with a very efficient solar to chemical energy conversion device under an incident solar flux of $100 \mathrm{~mW}$ $\mathrm{cm}^{-2}$. Obviously, the lower the overpotential for the OER the more efficient the overall cell, but the best WOCs are usually based on oxides of Ru or Ir, which are not abundant ${ }^{4}$. It is not surprising, therefore, that there has been a great deal of effort in recent years to identify new, alternative, inexpensive, i.e. Earth-abundant, highly active WOCs ${ }^{3}$.

As part of this effort, many new WOCs are, initially at least, generated in powder form, but their subsequent, reliable transformation into an anode and testing as an electrocatalyst for the oxidation of water is non-trivial and time-consuming ${ }^{6}$. It is also impractical for testing many different potential WOCs, which the increasingly employed combinatorial methods are very effective at producing ${ }^{7}$. Fortunately, a quick initial impression of the activity of a powdered WOC can be gleaned from its ability to mediate a redox reaction involving the oxidation of water, i.e. reaction (1).

$$
n \mathrm{Ox}+2 \mathrm{H}_{2} \mathrm{O} \longrightarrow n \text { Red }+4 \mathrm{H}^{+}+\mathrm{O}_{2} \uparrow
$$

Where $O x$ is the oxidant, Red is the reduced form of $O x$, and $n$ is the number of equivalents necessary to consume 4 electrons from water. Obviously, Ox must have 
an oxidation potential greater than that of water, i.e. $\mathrm{E}(\mathrm{Ox} / \mathrm{Red})>\mathrm{E}\left(\mathrm{O}_{2} / \mathrm{H}_{2} \mathrm{O}\right)$; where the latter is equal to $1.23-0.059 \mathrm{pH}$. Usually, the greater the difference, $\Delta \mathrm{E}$, the greater the value of $\Delta \mathrm{G}$ and the faster the process, until, that is, $\Delta \mathrm{E}$ is so large that the rate of reaction is limited by the rate of diffusion of $O x$ to the surface of the WOC catalyst particles ${ }^{8}$.

Reaction (1) is an example of redox catalysis, the understanding of which has been greatly advanced through the significant efforts of Spiro and his collaborators ${ }^{9,10}$. In particular, through an examination of over 70 different redox systems, they have demonstrated that the role of the redox catalyst is often simply that of a conductor of electrons, as illustrated in Figure 1 for the overall redox reaction, which in this case is the oxidation of water by a strong oxidant, $O x$, i.e. reaction $(1)^{8,9}$. It follows that the kinetics observed when using a WOC in powdered form as a redox catalyst for reaction (1) are usually related directly to its eventual performance as an electrocatalyst at the anode in a solar-driven, water-splitting cell. As a consequence, as noted by many groups $^{3,8}$, redox catalysis based on reaction (1) has great potential as a screening tool for powder-based WOCs and is becoming an increasingly popular method as such ${ }^{3}$.

In such studies ${ }^{3,8}$, the WOC is commonly dispersed in solution, and upon addition (or upon electrochemical or photochemical generation) of the oxidising chemical species, $O x$, the rate of reaction (1) is measured, usually spectrophotometrically via its subsequent decrease with time, at a rate which reflect the activity of the WOC. A common chemical oxidant in such work is $\mathrm{Ce}(\mathrm{IV})$, where $\mathrm{E}(\mathrm{Ce}(\mathrm{IV}) / \mathrm{Ce}(\mathrm{III}))=1.45 \mathrm{~V}$ in $0.5 \mathrm{M} \mathrm{H}_{2} \mathrm{SO}_{4}$, but its use is restricted to highly acidic conditions because it undergoes hydrolysis above $\mathrm{pH} 1$. In this system, the driving force for reaction (1), which is directly related to $\Delta \mathrm{G}^{\circ}$, is $\Delta \mathrm{E}=\left(\mathrm{E}^{\circ}(\mathrm{Ce}(\mathrm{IV}) / \mathrm{Ce}(\mathrm{III}))-\mathrm{E}^{\circ}\left(\mathrm{O}_{2} / \mathrm{H}_{2} \mathrm{O}\right)\right)=220 \mathrm{mV}$. Unfortunately, many of the current proposed 'Earth-abundant' oxygen catalysts, such as $\mathrm{CO}_{3} \mathrm{O}_{4}$ and $\mathrm{NiO}$, are unstable in acidic solution and so require an oxidant that can operate at much higher $\mathrm{pHs}^{3,4}$. 
If the WOC under test is stable and active under mildly acidic conditions, then the preferred, alternative oxidant to $\mathrm{Ce}(\mathrm{IV})$ is usually $\mathrm{Ru}(\mathrm{bpy}) 3_{3^{3+}}$, since $\mathrm{E}^{\mathrm{o}}\left(\mathrm{Ru}(\mathrm{bpy}) 3^{3+} / \mathrm{Ru}(\mathrm{bpy}) 3^{2+}\right)=1.26 \mathrm{~V}$. Ru(bpy) $3_{3^{3+}}$ can be generated chemically (using $\mathrm{Cl}_{2}$ or $\left.\mathrm{PbO}_{2}\right)^{11}$ or electrochemically, but, unfortunately, it is increasingly unstable with $\mathrm{pH}$ above $\mathrm{pH} 1^{12,13}$, and so, with increasing $\mathrm{pH}$, it becomes more difficult to store and use. As a result, most groups working on new WOCs choose to generate $\mathrm{Ru}(\mathrm{bpy}) 3^{3^{3+}}$ in situ, via the oxidative quenching of its electronically excited state by a sacrificial electron donor such as persulfate ${ }^{14,15}$ or $\mathrm{Co}$ (II) pentammine chloride ${ }^{16,17}$. Whatever the mode of $\mathrm{Ru}(\mathrm{bpy}) 3^{3+}$ generation, $\mathrm{Ru}(\mathrm{bpy}) 3^{3+}$ works best as the oxidant, $\mathrm{Ox}$, in reaction (1) over the range $\mathrm{pH} 3-5$, since much above $\mathrm{pH} 5$ it degrades rapidly with little or no generation of oxygen ${ }^{12,13,18}$ and much below $\mathrm{pH} 3, \Delta \mathrm{E} \quad$ (= $\left.\mathrm{E}\left(\mathrm{Ru}(\mathrm{bpy}) 3^{3+} / \mathrm{Ru}(\mathrm{bpy}) 3^{2+}\right)-\mathrm{E}\left(\mathrm{O}_{2} / \mathrm{H}_{2} \mathrm{O}\right)\right)$ is insufficient to drive reaction (1) at a easily measurable rate. Interestingly, even over the range $\mathrm{pH} 3-5$, typical maximum yields of $\mathrm{O}_{2}$ are usually $<70 \% \%^{12,13}$, which is in stark contrast to the $\mathrm{Ce}(\mathrm{IV})$ test system where they are usually $>90 \%$ for the same proven WOC, such as $\mathrm{RuO}_{2}^{8,19,20}$.

The problem of testing new WOCs with a redox system is exacerbated by the fact there are many reported ${ }^{3,4}$ very active WOCs that are only stable under conditions of high alkalinity (i.e. $\geq 0.1 \mathrm{M} \mathrm{OH}^{-}$), such as $\mathrm{Fe}_{2} \mathrm{O}_{3}$-doped $\mathrm{NiO}^{21}$ and, more recently, $\mathrm{Ni}_{2} \mathrm{P}$ (core)/ $/ \mathrm{NiO}_{x}$ (shell) particles ${ }^{22}$. In order to rapidly screen all WOCs, regardless of their $\mathrm{pH}$ stability, what is required is an oxidant that is able to effect reaction (1) in the presence of an established $W O C$ in acid, neutral and alkaline conditions. In this paper we report on the effective use of the two electron oxidant periodate in this role, as demonstrated using a highly reproducible, active, benchmark WOC, Ru(Adams), i.e. $\mathrm{RuO}_{2}$, prepared by a slightly modified version of the Adams method ${ }^{23}$.

Periodate has been used in the recent past to demonstrate the action of a number of different homogeneous WOCs ${ }^{24-27}$, but has been much less frequently used for testing heterogeneous $W_{O C s^{8,27}}$. The particular novelty of this work is not only the use of periodate as the oxidant in testing a heterogeneous WOC, but also, and more importantly, its use to assess its underlying activity via the spectrophotometric 
monitoring of the decay of the periodate to iodate, under conditions in which the oxidant is repeatedly in vast excess compared to the catalyst.

\section{Experimental}

All chemicals used were purchased from the Sigma-Aldrich Chemical Company. Doubly distilled and deionised water was used throughout. The $0.1 \mathrm{M} \mathrm{Ce}(\mathrm{IV})$ solution in sulphuric acid was used as received. The $0.1 \mathrm{M} \mathrm{NaIO}_{4}$ solution was freshly prepared on the day of the kinetic run or $\mathrm{O}_{2}$ evolution test. Powder XRD spectra of the Ru(Adams) catalyst were recorded using a Panalytical X'pert powder X-ray diffractometer with $\mathrm{Cu} \mathrm{K}_{\alpha}$ radiation $(\lambda=1.5406 \mathrm{~nm})$ at $40 \mathrm{kV}$ and $40 \mathrm{~mA}$ with a step size of $0.02^{\circ}$.

\subsection{Preparation of Ru(Adams)}

In the slightly modified preparation of Ru-Adams ${ }^{23}, 0.5 \mathrm{~g} \mathrm{RuCl}_{3} \cdot \mathrm{XH}_{2} \mathrm{O}$ and $10 \mathrm{~g} \mathrm{NaNO}_{3}$ were dissolved in $15 \mathrm{~mL}$ water. The resulting solution was placed in a crucible and heated at $500^{\circ} \mathrm{C}$ for $25 \mathrm{~min}$ in a muffle furnace. The obtained melt was then allowed to cool before $80 \mathrm{~mL}$ of water were added to dissolve the $\mathrm{NaNO}_{3}$ in the $\mathrm{Ru}$ (Adams)/NaNO 3 cake. The black, finely divided, Ru-Adams catalyst powder was then filtered off, washed thoroughly with water, and dried in air. Figure 2 illustrates a typical XRD powder pattern recorded for the Ru(Adams) powder, along with that reported in the literature ${ }^{28}$ for $\mathrm{RuO}_{2}$, which was used to confirm its identity. $\mathrm{N}_{2} \mathrm{BET}$ analysis of the powder, carried out using a Micromeritics Tristar 3020, revealed a specific surface area of ca. $150 \mathrm{~m}^{2} \mathrm{~g}^{-1}$. A typical dispersion of the Ru(Adams) was prepared by adding $3 \mathrm{mg}$ of the Ru(Adams) to $50 \mathrm{~mL}$ of the aqueous solution under test (i.e. $0.5 \mathrm{M} \mathrm{H}_{2} \mathrm{SO}_{4}$, water or $0.1 \mathrm{M} \mathrm{KOH}$, for work carried out under acidic, neutral and alkaline conditions, respectively). The suspension was subjected to ultrasound using an ultrasonic bath (Grant XUBA3) for 15 min and then stirred overnight to create a very stable dispersion that exhibited a typical background absorption ( $\triangle \mathrm{AbS} 800)$ of 0.12 at $800 \mathrm{~nm}$.

\subsection{Monitoring the kinetics of photocatalysis}


In a typical experiment, $2.5 \mathrm{~mL}$ of the $60 \mathrm{mg} \mathrm{L}^{-1} \mathrm{Ru}$ (Adams) catalyst were placed in a quartz cuvette, which was in turn placed in a UV/Visible spectrophotometer (Perkin Elmer Lambda 35). The removable sample holder plate of the latter instrument was replaced with a magnetic stirrer to allow for the continuous (ca. $800 \mathrm{rpm}$ ) stirring of the cuvette's contents. The absorbance of the dispersion was monitored at a wavelength that was suitable for monitoring the concentration of the oxidant under test $(430 \mathrm{~nm}$ for $\mathrm{Ce}(\mathrm{IV})$ and $280 \mathrm{~nm}$ for periodate) as function of time. After $5 \mathrm{~min}$ of monitoring the absorbance, the redox catalytic reaction was initiated by the injection of $90 \mu \mathrm{L}$ of a 0.1 M solution of the oxidant under test. The decay of the oxidant was continuously monitored spectrophotometrically until no further, significant decay in absorbance was observed and the reaction was deemed complete. In all cases, i.e. whatever the oxidant and $\mathrm{pH}$, no decay of the oxidant was observed over the time course of the kinetic runs in the absence of the $\mathrm{Ru}($ Adams) catalyst.

\subsection{Monitoring the generation of oxygen}

The evolution of oxygen arising from reaction (1) was monitored manometrically using a $125 \mathrm{~mL}$ Drechsel bottle equipped with a pressure transducer sealed in its top, and a rubber septum side injection port which allowed the introduction of the WOC catalyst, here a $2.5 \mathrm{~mL}$ dispersion of $12 \mathrm{mg}$ of $\mathrm{Ru}$ (Adams), into $100 \mathrm{~mL}$ of a $3.6 \mathrm{mM}$ solution of the oxidant under test ${ }^{8}$. Upon addition of the catalyst dispersion to the sealed Drechsel bottle, the pressure change in the head space was monitored as a function of time until no further increase in pressure due to gas evolution was observed. At this point the overall change in pressure due to gas evolution was measured and used to calculate the number of moles of $\mathrm{O}_{2}$ generated. In other work, for each of the Drechsel-based, gas-generating runs conducted at different $\mathrm{pH}$, the identity and level of $\mathrm{O}_{2}$ generated was confirmed by gas chromatography using a Shimadzu GC-2014 instrument equipped with a thermal conductivity detector (TCD) operated at $140^{\circ} \mathrm{C}$ and an $1.8 \mathrm{~m}$-long Alltech CTR-1 column heated to $32^{\circ} \mathrm{C}$, with a $65 \mathrm{~mL} \mathrm{~min}^{-1}$ flow of Ar as the carrier gas.

\section{Results and Discussion}




\subsection{Ce(IV) in acid}

As noted earlier, a past common route to assessing the activity of a powdered potential $W O C$, if stable under acidic conditions, would be to disperse it into $2.5 \mathrm{~mL}$ of $0.5 \mathrm{M}$ $\mathrm{H}_{2} \mathrm{SO}_{4}$ (60 $\mathrm{mg} \mathrm{L}^{-1}$, here) and monitor the kinetics of Ce(IV) decay caused by reaction (1) spectrophotometrically, after the injection of $90 \mu \mathrm{L}$ of $0.1 \mathrm{M} \mathrm{Ce}(\mathrm{IV})$ in $0.5 \mathrm{M} \mathrm{H}_{2} \mathrm{SO}_{4}$ into the catalyst dispersion. Previous work carried out by this group has established that one of the best WOCs for reaction (1) is Ru(Adams) ${ }^{23}$. In this work, the preparation of $\mathrm{Ru}$ (Adams) has been modified slightly compared to that reported earlier, so as to generate a more reproducible, higher surface area $\left(150 \mathrm{~m}^{2}\right.$ $\mathrm{g}^{-1}$ compared to $\left.113 \mathrm{~m}^{2} \mathrm{~g}^{-1}\right)^{23}$ WOC. This material is ideal for testing out other potential oxidants that offer an alternative to $\mathrm{Ce}(\mathrm{IV})$, such as periodate, at any $\mathrm{pH}$. $\mathrm{Ru}$ (Adams) also appears to be a suitable benchmark material with which to compare the performance of other, powdered, alternative new WOCs.

Figure 3 illustrates the typical observed change in the spectrum of the $\mathrm{Ce}(\mathrm{IV}) / \mathrm{Ru}$ (Adams) system as a function of time upon the first injection of Ce(IV) solution into a dispersion of Ru(Adams). As can be seen from the data in figure 3, the dispersion of Ru(Adams) - a black powdered WOC, spectrophotometrically simply provides a grey background, and so constant absorbance, at all wavelengths, as the $\mathrm{Ce}(\mathrm{IV})$ concentration, [Ce(IV)], decays due to reaction (1). As a consequence, this allows the decay in [Ce(IV)] due to reaction (1) to be monitored spectrophotometrically, and so the kinetics of water oxidation to be measured. The wavelength used for this purpose, $430 \mathrm{~nm}$, is highlighted in figure 3 by the vertical broken red line. The insert diagram illustrates the measured variation in absorbance at $430 \mathrm{~nm}$ of the same 60 $\mathrm{mg} \mathrm{L}^{-1}$ dispersion of $\mathrm{Ru}$ (Adams) for a series of repeat injections of $\mathrm{Ce}(\mathrm{IV})$, in which the three observed decay profiles are due solely to the changes in [Ce(IV)] caused by reaction (1).

The decay profiles illustrated in figure 3 are easily recorded and provide a great deal of useful information. For example, if no decay in Ce(IV) absorbance is observed then it would appear that the powdered potential WOC under test is not a promising WOC, 
most likely because it has an high over-potential for water oxidation. However, little or no observed WOC activity may also be observed if the WOC under test forms a poor dispersion, as is often the case for highly crystalline materials with low $\left(<10 \mathrm{~m}^{2}\right.$ $\mathrm{g}^{-1}$ ) specific surface $\operatorname{areas}^{8,29}$. Obviously, one way to attempt to address such a problem would be to use a much higher concentration of the WOC.

Clearly, for the best results, the WOC under test has to be well-dispersed, and a quick and useful method to assess quickly, albeit crudely, the extent and stability of the WOC dispersion is to monitor its absorbance at a wavelength where the oxidant does not absorb, say $800 \mathrm{~nm}^{30,31}$. Ideally, for a well dispersed powder such as Ru(Adams), the absorbance due to the catalyst dispersion, $\Delta$ Abs800, should be $>0.1$ (for Ru(Adams) it is typically ca. 0.12) and should not change during the course of a kinetic run. If, for any potential WOC catalyst under test, the value of $\triangle A b s 800$ is found to be much less than 0.1 , then the powder is poorly dispersed and the potential WOC is unlikely to exhibit much, if any, activity. Under such circumstances, a higher concentration of catalyst is likely to be needed, or the aggregated particles may need to be broken up more, through ball-milling or the use of ultrasound. The variation in $\Delta$ Abs8oo over the time course of a kinetic run can also be very informative. For example, if, as often happens for some metal oxides such as $\mathrm{MnO}_{2}$, the value of $\Delta \mathrm{Abs} 800$ drops significantly, then this is may be taken as evidence of catalyst particle aggregation and precipitation, i.e. the powdered WOC dispersion is not sufficiently stable. In many such instances, the initial degree of aggregation and the tendency of the WOC particles to aggregate can be improved greatly though the use of an inert anti-flocculating agent, such as silica ${ }^{32}$.

From the decay profiles illustrated in figure 3, for the Ce(IV)/Ru(Adams) Ox/WOC system, it appears that: (i) Ru(Adams) is effective in mediating reaction (1), when $O x$ $=\mathrm{Ce}(\mathrm{IV})$ and (ii) the catalyst dispersion is stable over the time course of the three injections. Recording the decay profiles over at least 3 injections of oxidant is useful as it reveals whether the WOC remains consistently active or not with repeated use. For example, if, upon injection, [Ce(IV)] is found to decay a little and then stop or slow 
down considerably, this would suggest that the WOC has been quickly rendered inactive and/or subject to anodic corrosion. Interestingly, the latter effect will also usually manifest itself by a significant drop in the initial value of $\Delta \mathrm{AbS} 800$ upon the initial injection of the oxidant. Indeed, this is observed when highly hydrated $\mathrm{RuO}_{2}$, i.e. $\mathrm{RuO}_{2} . x \mathrm{H}_{2} \mathrm{O}$, is used in the $\mathrm{Ce}(\mathrm{IV}) / W O C$ test system, since the latter is more readily oxidised to $\mathrm{RuO}_{4}$ by the $\mathrm{Ce}(\mathrm{IV})$ than able to mediate reaction (1) ${ }^{33}$. Only upon heattreating the $\mathrm{RuO}_{2} \cdot \mathrm{xH}_{2} \mathrm{O}$ (thermal activation) is it rendered stable and active as a WOC $^{34}$.

A closer inspection of the decay profiles illustrated in figure 3 reveals that the rate of decay of [Ce(IV)] decreases with each injection. Indeed, an analysis of each of the three decays in [Ce(IV)] illustrated in figure 3 on the basis of first order kinetics over one half-life yields increasing values for the first order rate constant, $k_{1}$, as shown in Table 1. Table 1 also contains the values of the first order decay fit correlation coefficients $\left(R^{2}\right)$ and the initial values of $\Delta$ Abs800 obtained for the three decays illustrated in figure 3. Previous work conducted on this system has shown that this apparent decay in activity is actually due to the accumulation of $\mathrm{Ce}(\mathrm{III})$, which lowers the redox potential of the $\mathrm{Ce}(\mathrm{IV}) / \mathrm{Ce}$ (III) couple, as predicted by the Nernst equation, which in turn reduces the value of $\Delta \mathrm{E}$ to such an extent as to adversely affect the kinetics of reaction $(1)^{35}$. These previous studies have shown that it is possible to fit the observed kinetics of decay exhibited by the Ru(Adams), for all three injections and more, to those predicted by an electrochemical model based on the Nernstian highly reversible reduction of $\mathrm{Ce}(\mathrm{IV})$ coupled to the irreversible oxidation of water ${ }^{35}$. However, such an analysis is quite involved and unnecessary here, given that the purpose of the test systems under study is to provide a quick and simple assessment of the WOC activity of the powdered material under test. As a consequence, here we focus on just the first of the three values of $k_{1}$ given in Table 1 for the Ce(IV) system, i.e. that for the $1^{\text {st }}$ injection, since it is associated with the kinetics of reaction (1) which are least affected by the level of $\mathrm{Ce}$ (III) present and which, from previous studies ${ }^{35}$, is near to that expected if the rate of reaction were controlled by the diffusion of the $\mathrm{Ce}(\mathrm{IV})$ ions to the surface of the Ru(Adams) particles. As such, this value of $k_{1}$ (ca. 
$0.33 \mathrm{~min}^{-1}$, see Table 1 ) is not so much a measure of the fundamental WOC activity of Ru(Adams) but more a measure of the effective surface area of the aggregated dispersed particles ${ }^{19,20}$. It follows that, when using another oxidant, such as periodate at any $\mathrm{pH}$, rather than $\mathrm{Ce}(\mathrm{IV})$ in acid, with the same catalyst, which presumably disperses to the same or similar extent (as crudely assessed by the value of $\Delta \mathrm{Abs} 800$ (= ca. 0.12 for the Ce(IV) system)), then, if the measured value of $k_{1}$ is $<<0.33 \mathrm{~min}^{-1}$, the reaction is probably activation- rather than diffusion-controlled ${ }^{19,20}$.

The Ce(IV)/Ce(III) redox system is a well-known reversible redox system ${ }^{36}$ and so the redox potential, i.e. the mixture potential, $E_{\text {mix }}$, it imposes on the Ru(Adams) particles will reflect the ratio of $\mathrm{Ce}(\mathrm{IV})$ to $\mathrm{Ce}(\mathrm{III})$ at the surface of the catalyst particles, via the Nernst equation. In the electrochemical model of redox catalysis, at $E_{\text {mix }}$ the rate of oxidation of water (the anodic current) on a catalyst particle is equal to the rate of reduction of $\mathrm{Ce}(\mathrm{IV})$, the cathodic current ${ }^{35}$. In such a system, if $\Delta \mathrm{E}$ is sufficiently large, and $[\mathrm{Ce}(\mathrm{III})]$ small, as in the $1^{\text {st }}$ injection in figure 3 , then the rate of reaction is limited by the rate of diffusion of the $\mathrm{Ce}(\mathrm{IV})$ ions to the redox catalyst particles. A schematic illustration of current-voltage curves associated with this coupling of the two redox systems via a redox catalyst is given in figure $4^{35}$.

The first-order rate constant, $k_{D}$ (units: $\mathrm{s}^{-1}$ ), for a diffusion-controlled reaction between the $\mathrm{Ce}(\mathrm{IV})$ ions and an aggregated $\mathrm{Ru}$ (Adams) particle can be calculated using a modified version of the Smoluchowski equation ${ }^{37}$,

$$
k_{D}=12 D[\mathrm{Ru}(\text { Adams })] /\left(1000 \rho d^{2}\right)
$$

where $\boldsymbol{D}$ is the diffusion coefficient of the Ce(IV) ions (assumed ${ }^{37}$ to be $1 \times 10^{-5} \mathrm{~cm}^{-2}$ $\left.\mathrm{s}^{-1}\right),\left[\mathrm{Ru}\left(\right.\right.$ Adams] is the concentration of catalyst $\left(0.06 \mathrm{~g} \mathrm{~L}^{-1}\right), \rho$ is the density of the aggregated $\mathrm{RuO}_{2}$ particle (assumed to be that of bulk $\mathrm{RuO}_{2}$ itself, $6.97 \mathrm{~g} \mathrm{~cm}^{-3}$ ) and $d$ is the average diameter of the aggregated catalyst particles $(\mathrm{cm})$. A value for the aggregated Ru(Adams) particles of $4.3 \mu \mathrm{m}$ can be calculated using eqn (2) based on a $k_{1}$ value of $0.33 \mathrm{~min}^{-1}$, i.e. $5.5 \times 10^{-3} \mathrm{~s}^{-1}$. This value compares favourably to that of $11 \pm 6 \mu \mathrm{m}$ measured using optical microscopy ${ }^{19}$ for a similar dispersion of $\mathrm{RuO}_{2}$, given that the calculation of $d$ via eqn (2) is based on the assumption that the density of the 
aggregated $\mathrm{Ru}\left(\right.$ Adams) particles is that of bulk $\mathrm{RuO}_{2}$, when in fact it will be much less, and so the value of $d$ will be much greater than $4.3 \mu \mathrm{m}$, as is found.

In the $\mathrm{Ce}(\mathrm{IV}) / \mathrm{Ru}($ Adams) system, the three serial decay profiles, each one largely to completion, illustrated in figure 3, coupled with the fact that after each injection the number of moles of initial oxidant $(9.0 \mu$ moles $)$ is in vast excess to that of WOC present (1.1 $\mu$ moles), help establish the redox catalyst credentials of the Ru(Adams) in terms of turnover number; $T N$, defined here as the ratio of number of moles of oxidising equivalents consumed to number of moles of catalyst used. From the data in figure 3 , the value of $T N$ appears to be $>32$. For any potential new WOC, a value $>4$ is essential, but the greater the value above 4, the more reassuring it is that the catalyst is stable, active and deserving of the sobriquet 'WOC'. Clearly, no material can be claimed to be a WOC, although some have ${ }^{38}$, if the amount of redox catalyst used is in vast excess compared to the oxidant present.

Finally, no claim of WOC activity would be complete without establishing that the decay of $O x$ in reaction (1) is accompanied by the generation of stoichiometric amounts of $\mathrm{O}_{2}$. The latter is established here using the manometric system described earlier, in which a $2.5 \mathrm{~mL}$ dispersion of $12 \mathrm{mg}$ of $\mathrm{Ru}$ (Adams) is injected into $100 \mathrm{~mL}$ of a $3.6 \mathrm{mM}$ solution of the oxidant under test, in a sealed system, and any subsequent gas evolution monitored by the increase in internal pressure. Using this system, the pressure change was recorded as a function of time after injection for $O x=\mathrm{Ce}(\mathrm{IV})$, and the results are illustrated in figure 5. From this data, and knowledge that: (i) a 2 $\mathrm{mL}$ injection of air into the same, sealed system produced a change in pressure of 26 mbar, and (ii) the overall change in pressure recorded in figure 5 is 26.2 mbar, then the number of moles of gas liberated was calculated to be $82.3 \mu$ moles. As noted in the experimental section, additional experiments conducted using GC confirmed that the gas evolved was $\mathrm{O}_{2}$ and confirmed the total number of moles of $\mathrm{O}_{2}$ liberated as determined manometrically. Given that in this experiment $360 \mu$ moles of $\mathrm{Ce}(\mathrm{IV})$ were consumed, and so $90 \mu$ moles of $\mathrm{O}_{2}$ should have been generated, it follows that, for the $\mathrm{Ce}(\mathrm{IV}) / \mathrm{Ru}$ (Adams) system, the $\% \mathrm{O}_{2}$ yield for reaction (1) is $91 \%$. Further work 
revealed no evidence of catalyst corrosion (due to $\mathrm{RuO}_{4}$ formation, for example), and, as a consequence, the observed decays of $\mathrm{Ce}$ (IV) in figure 3 are attributed to the catalysed oxidation of water via reaction (1), mediated by the Ru(Adams) catalyst.

\subsection{Periodate in acid}

Under the acidic conditions used here, i.e. $0.5 \mathrm{M} \mathrm{H}_{2} \mathrm{SO}_{4}$, periodate exists as periodic acid, $\mathrm{H}_{5} \mathrm{O}_{6}\left(\mathrm{pK}_{\mathrm{a}}=3.29\right)^{39}$ and has a redox potential $\left(\mathrm{E}^{\mathrm{O}}\left(\mathrm{H}_{5} \mathrm{IO}_{6} / \mathrm{HIO}_{3}\right)=1.626 \mathrm{~V}\right)^{40}$ that yields a value for $\Delta \mathrm{E}=396 \mathrm{mV}$, which is much greater than that for the $\mathrm{Ce}(\mathrm{IV}) / \mathrm{Ce}(\mathrm{III})$ couple in sulphuric acid $(\Delta \mathrm{E}=220 \mathrm{mV})^{36}$, vide infra. Using the standard kinetic system described earlier, a series of UV/Vis spectra were recorded as a function of time upon injection of $90 \mu \mathrm{L}$ of a $0.1 \mathrm{M}$ solution of sodium periodate into $2.5 \mathrm{~mL}$ of the $60 \mathrm{mg} \mathrm{L}^{-1}$ $\mathrm{Ru}$ (Adams) catalyst in $0.5 \mathrm{M} \mathrm{H}_{2} \mathrm{SO}_{4}$, and are illustrated in figure 6 . The results show that $\left[\mathrm{H}_{5} \mathrm{O}_{6}\right]$ decays as a function of time and can be monitored spectrophotometrically at a wavelength of $280 \mathrm{~nm}$, which is highlighted by the broken red line in figure 6 . The results for three sequential injections of $\mathrm{H}_{5} \mathrm{IO}_{6}$ into the same, standard dispersion of $\mathrm{Ru}$ (Adams) are illustrated by the decay profiles in the insert diagram in figure 6 .

A first order analysis of each of these decays over two half-lives reveals the kinetics of each decay to be similar and of good first order, with values for $k_{1}$ given in table 1 and an average value for $k_{1}$ of $0.09 \mathrm{~min}^{-1}$. Unlike the Ce(IV) system, there is no evidence that the reduced form of periodate, i.e. iodate, impedes the kinetics of reduction of the periodic acid, and this appears true for all pHs studied. Since the rates of decay for the three profiles are similar and reasonably first order, this initially suggests that the kinetics might be diffusion-controlled. However, because the values for $k_{1}$ (for example $=0.094 \mathrm{~min}^{-1}$ for the first injection for periodic acid, see Table 1) are much less than that measured for the Ce(IV) system $\left(0.33 \mathrm{~min}^{-1}\right)$, which is for a diffusion-controlled reaction, and the values for $\triangle \mathrm{AbS} 800$ are necessarily similar (ca. 0.12 ) for both systems, it follows that the kinetics for reaction (1) in acid where $O x=$ $\mathrm{H}_{5} \mathrm{IO}_{6}$ are not wholly diffusion-controlled, but rather are most likely largely activationcontrolled. 
The lack of diffusion-controlled kinetics for the $\mathrm{H}_{5} \mathrm{IO}_{6} / \mathrm{Ru}$ (Adams) version of reaction (1) may appear surprising at first, given that $\Delta \mathrm{E}=396 \mathrm{mV}$ compared with $220 \mathrm{mV}$ when $\mathrm{Ox}=\mathrm{H}_{5} \mathrm{IO}_{6}$ and $\mathrm{Ce}(\mathrm{IV})$, respectively. However, because of the irreversible nature of the $\mathrm{H}_{5} \mathrm{IO}_{6} / \mathrm{HIO}_{3}$ redox couple, its clear thermodynamic advantage over the $\mathrm{Ce}(\mathrm{IV})$ system is largely lost as a significant overpotential is required to effect the reduction of the periodic acid on the surface of the Ru(Adams) catalyst particles. As a consequence, despite the large value for $\Delta \mathrm{E}$ for the $\mathrm{H}_{5} \mathrm{IO}_{6} / \mathrm{HIO}_{3}$ system, the observed kinetics are activation and not diffusion-controlled and the kinetics are not affected by the iodate generated. Figure 4 provides a schematic illustration of this situation, in which the irreversible reduction of an oxidant, $O x_{2}$, is coupled to the oxidation of water via a redox catalyst, so that the mixture current flowing through the particles is less than that expected for a diffusion-controlled process, despite the very large value for $\Delta \mathrm{E}$, as is the case for reaction (1) when $\mathrm{Ox}_{x}=\mathrm{H}_{5} \mathrm{IO}_{6}$. Note that if the value of $\mathrm{E}\left(\mathrm{Ox}_{2} / \mathrm{Red}_{2}\right)$ could be increased, then $\Delta \mathrm{E}$ would be increased and the observed rate of reaction would also be increased, and if this increase was sufficient, then diffusion-controlled kinetics would be observed. Similarly, if $\Delta \mathrm{E}$ were decreased then the observed rate would be greatly reduced and the kinetics would become much more obviously activation-controlled. The relevance of the latter observations becomes apparent when the observed kinetics of reaction (1) with periodate as the oxidant in water and alkali are considered.

As before, the amount of gas evolved via reaction (1) with, this time, $\mathrm{O} x=\mathrm{H}_{5} \mathrm{IO}_{6}$, was measured using the manometric system, and the results are illustrated in figure 5. From this data it can be gleaned that the overall change in pressure recorded was 59.2 mbar, and so $173 \mu$ moles of $\mathrm{O}_{2}$ were liberated. Given that, in this experiment, $360 \mu$ moles of $\mathrm{H}_{5} \mathrm{IO}_{6}$ were consumed via reaction (1) and so $180 \mu$ moles of $\mathrm{O}_{2}$ should have been generated, it follows that for this $\mathrm{H}_{5} \mathrm{IO}_{6} / \mathrm{Ru}$ (Adams) system the $\% \mathrm{O}_{2}$ yield for reaction (1) is $96 \%$. As a consequence, the observed decays of $\mathrm{H}_{5} \mathrm{IO}_{6}$ illustrated in figure 6 are attributed to the catalysed oxidation of water via reaction (1), mediated by the $\mathrm{Ru}\left(\right.$ Adams) catalyst, with $\mathrm{Ox}=\mathrm{H}_{5} \mathrm{IO}_{6}$. Given that periodic acid is a $2 \mathrm{e}^{-}$oxidant, and generates near stoichiometric amounts of $\mathrm{O}_{2}$ in three successive injections (figure 
5 and 6) it follows that the turnover for reaction (1) in acid, where Ox = periodic acid, is $>64$, as also appears to be the case in water and strong alkali, vide infra.

\subsection{Periodate in water and strong alkali}

The $\mathrm{pH}$ of a typical $60 \mathrm{mg} \mathrm{L}^{-1}$ dispersion of $\mathrm{Ru}($ Adams) in water is ca. $\mathrm{pH} \mathrm{6}$, and at this $\mathrm{pH}$ periodate exists in its metaperiodate form ${ }^{39,40}$, i.e. as $\mathrm{IO}_{4}^{-}$, since the $\mathrm{pK}_{\mathrm{a}} \mathrm{Of}_{5} \mathrm{H}_{5} \mathrm{O}_{6}$ is 3 and $\mathrm{K}=29$ for the equilibrium between $\mathrm{H}_{4} \mathrm{IO}_{6}{ }^{-}$and $\mathrm{IO}_{4}{ }^{-39}$. At $\mathrm{pH} 6, \mathrm{E}\left(\mathrm{IO}_{4}{ }^{-} / \mathrm{IO}_{3}{ }^{-}\right)$ $=1.298 \mathrm{~V}^{40}$ and $\mathrm{E}\left(\mathrm{O}_{2} / \mathrm{H}_{2} \mathrm{O}\right)=0.875 \mathrm{~V}$, so that $\Delta \mathrm{E}=423 \mathrm{mV}$, i.e. greater than that for periodate in acid. Using otherwise the same conditions as used in the study of reaction (1) in acid (see section 3.2), the kinetics of reaction (1) with $O x=1 \mathrm{O}_{4}^{-}$were studied spectrophotometrically via a sequence of three $90 \mu \mathrm{L}$ injections of a $0.1 \mathrm{M} \mathrm{NalO}_{4}$ solution into $2.5 \mathrm{~mL}$ of an aqueous dispersion of $\mathrm{Ru}$ (Adams). The resulting 3 decay profiles are illustrated in figure $7(\mathrm{a})$, and each provide excellent fits to first order kinetics over two half-lives, yielding the $k_{1}$ and $r^{2}$ values given in Table 1 . The former are a little bigger than the benchmark value of $0.33 \mathrm{~min}^{-1}$ found for $\mathrm{Ce}(\mathrm{IV})$ and previously associated with diffusion-controlled kinetics. However, this slight increase may be due, in part at least, to the Ru(Adams) forming a better dispersion in water than in acid, since: $\Delta \mathrm{AbS} 800=\mathrm{ca} .0 .14$ for the $1^{\text {st }}$ injection in water compared with 0.12 in acid with $\mathrm{Ce}(\mathrm{IV})$. As a consequence, given the excellent first order nature of the kinetics and comparable value for $k_{1}$ to that for the Ce(IV) in acid system, it is very likely that in water the kinetics of reaction (1) with $\mathrm{Ox}=\mathrm{IO}_{4}^{-}$are diffusion-controlled. This is not too improbable, given that a small shift in $\Delta \mathrm{E}$ (in this case from 396 to 423 $\mathrm{mV}$ ) can bring about a striking change in electrochemical kinetics, in this case from activation to diffusion control, as illustrated in figure 4. A manometric study revealed an $\% \mathrm{O}_{2}$ yield of $92 \%$, confirming that the reaction under study in water was reaction (1), with $\mathrm{Ox}=\mathrm{IO}_{4}^{-}$.

In strong alkali, i.e. 0.1 $\mathrm{M} \mathrm{KOH}$, periodate exists as $\mathrm{H}_{3} \mathrm{IO}_{6}{ }^{2-}$ and although this species has a tendency to dimerise ${ }^{41}$, the dimerisation constant is not particularly large (ca. $\left.142 \mathrm{M}^{-1}\right)^{41}$ and the final concentration used in this work is low $\left(3.6 \times 10^{-3} \mathrm{M}\right)$, so $\mathrm{H}_{3} \mathrm{IO}_{6}{ }^{2-}$ can be taken to be the major species present. At pH 13, $\mathrm{E}\left(\mathrm{H}_{3} \mid \mathrm{O}_{6}{ }^{2-} / \mathrm{IO}_{3}{ }^{-}\right)=0.686 \mathrm{~V}^{39}$, 
and $\mathrm{E}\left(\mathrm{O}_{2} / \mathrm{H}_{2} \mathrm{O}\right)=0.462$, so $\Delta \mathrm{E}=224 \mathrm{mV}$, i.e. much less than that for periodate in acid (396 mV). As a consequence, it is not too surprising that the decays of $\mathrm{H}_{3} \mathrm{IO}_{6}{ }^{2-}$ via reaction (1), as monitored spectrophotometrically under otherwise the same conditions as before, although very similar from run to run, were also very slow, and much slower than observed at the other two pHs studied. For example, in alkali the value for $k_{1}$ for the first injection was found to be ca. $0.021 \mathrm{~min}^{-1}$, whereas in water it was ca. 23 times bigger $\left(0.489 \mathrm{~min}^{-1}\right)$. This considerable decrease in apparent catalytic activity is attributed to the much lower thermodynamic driving force, as measured by $\Delta \mathrm{E}$, when reaction (1) is carried out in alkali $(\mathrm{pH} 13)$ compared with in water ( $\mathrm{pH}$ 6). Once again a manometric study revealed an $\% \mathrm{O}_{2}$ yield of ca. $96 \%$, confirming that under very alkaline conditions the reaction under study was reaction (1) when $\mathrm{Ox}=\mathrm{H}_{3} \mathrm{IO}_{6}{ }^{2-}$.

\section{Conclusions}

$\mathrm{Ru}$ (Adams) is able to act as a WOC in mediating reaction (1) using as Ox either: (i) $\mathrm{Ce}\left(\mathrm{IV}\right.$ ) in $0.5 \mathrm{M} \mathrm{H}_{2} \mathrm{SO}_{4}$ or (ii) periodate in $0.5 \mathrm{M} \mathrm{H}_{2} \mathrm{SO}_{4}$, water and $0.1 \mathrm{M} \mathrm{KOH}$. The use of periodate, in contrast to Ce(IV), as the oxidant allows the WOC activity of a wide range of materials that are not stable in acid, such as $\mathrm{Fe}_{2} \mathrm{O}_{3}$-doped $\mathrm{NiO}, \mathrm{CO}_{3} \mathrm{O}_{4}$ and, more recently, $\mathrm{Ni}_{2} \mathrm{P}$ (core)/NiO(shell) to be quickly assessed for WOC activity in water or aqueous alkali in powder form. The use of periodate in water for testing WOC activity appears particularly promising, given that the electrochemical driving force, $\Delta \mathrm{E}$, is sufficiently large ( $423 \mathrm{mV})$ that the kinetics are controlled by the rate of diffusion of the periodate ions to the surface of the Ru(Adams) catalyst particles. Although most alternatives to PGM oxide WOCs will exhibit a higher overpotential for water oxidation than $\mathrm{Ru}$ (Adams), a value of $\Delta \mathrm{E}=423 \mathrm{mV}$ in water may be sufficient to use periodate as $O x$ in reaction (1) for demonstrating their WOC activity, although this likely higher overpotential means that the observed kinetics are similarly less likely to be diffusioncontrolled. In contrast, under alkaline conditions, $\Delta \mathrm{E}$ is only $224 \mathrm{mV}$ and so only very active WOCs with very low overpotentials for water oxidation, as found for Ru(Adams) and the oxides of Ru and Ir in general, will be able to mediate reaction (1) so as to effect an easy to measure rate of decay in $\left[\mathrm{H}_{3} \mathrm{IO}_{6}{ }^{2-}\right]$. Interestingly, the 
$\mathrm{Ni}_{2} \mathrm{P}$ (core)/NiO(shell) particles reported recently by $\mathrm{Hu}$ and his co-workers claim an overpotential in $\mathrm{KOH}$, of $290 \mathrm{mV}$ for $10 \mathrm{~mA} \mathrm{~cm}^{-2}$, which is lower than that exhibited by commercially used $\mathrm{IrO}_{2}$ anodes. This observation suggests that such particles might well be able to effect reaction (1) in $0.1 \mathrm{M} \mathrm{KOH}$ when $\mathrm{Ox}=\mathrm{H}_{3} \mathrm{IO}_{6}{ }^{2-}$. The above findings should prove useful to the many groups investigating new WOCs and requiring a rapid screening method that is suitable for testing materials that are stable only under near neutral and/or alkaline conditions. 


\section{References}

1 N. S. Lewis, D. G. Nocera, Proc. Natl. Acad. Sci. USA, 2006, 103, 1572915735.

2 H-J. Lewerenz, L. Peter, Photoelectrochemical Water Splitting: Materials, Processes and Architectures, RSC Publishing, Cambridge, 2013.

3 J. R. Galán-Mascarós, ChemElectroChem, 2015, 2, 37-50.

4 M. G. Walter, E. L. Warren, J. R. McKone, S. W. Boettcher, Q. Mi, E. A. Santori, N. S. Lewis, Chem. Rev., 2010, 110, 6446-6473.

5 Y. W. Chen, J. D. Prange, S. Dühnen, Y. Park, M. Gunji, C. E. D. Chidsey, P. C. McIntyre, Nat. Mater., 2011, 10, 539-544.

6 J-I Jung, H. Y. Jeong, J-S Lee, M. G. Kim, J. Cho, Angew. Chem. Int. Ed., 2014, 53, 4582-4586.

7 J. E. Katz, T. R. Gingrich, E. A. Santori, N. S. Lewis, Energy Environ. Sci., 2009, 2, 103-112.

8 A. Mills, Chem. Soc. Rev. 1989, 18, 285-316.

9 M. Spiro, Chem. Soc. Rev. 1986, 15, 141-165.

10 M. Spiro, A. B. Ravnö, J. Chem. Soc., 1965, 78-96.

11 N. Sutin, C. Creutz, Pure Appl. Chem., 1980, 52, 2717-2738.

12 A. Mills, T. Russell, in Electrochemistry in Colloids and Dispersions, ed. R. A. Mackay, J. Texter, VCH Publishers, Inc., New York, 1992, ch. 32, pp. 431-445.

13 V. Y. Shafirovich, V. V. Strelets, Nouv. J. Chim., 1982, 6, 183-186.

14 F. Bolletta, A. Juris, M. Maestri, D. Sandrini, Inorg. Chim. Acta, 1980, 44, L175L176.

15 A. Harriman, I. J. Pickering, J. M. Thomas, P. A. Christensen, J. Chem. Soc., Faraday Trans. 1, 1988, 84, 2795-2806.

16 J. M. Lehn, J. P. Sauvage, R. Ziessel, Nouv. J. Chim., 1980, 4, 355-358.

17 A. Harriman, G. Porter, P. Walters, J. Chem. Soc., Faraday Trans. 2, 1981, 77, 2373-2383.

18 P. A. Christensen, W. Erbs, A. Harriman, J. Chem. Soc., Faraday Trans. 2, 1985, 81, 575-580.

19 A. Mills, S. Giddings, I. Patel, C. Lawrence, J. Chem. Soc., Faraday Trans. 1, 1987, 83, 2331-2345. 
A. Mills, S. Giddings, Inorg. Chim. Acta, 1989, 158, 49-57.

E. L. Miller, R. E. Rocheleau, J. Electrochem. Soc., 1997, 144, 3072-3077.

L-A. Stern, L. Feng, F. Song, X. Hu, Energy Environ. Sci., 2015, 8, 2347-2351.

A. Mills, H. L. Davies, Electrochim. Acta, 1992, 37, 1217-1225.

J. L. Fillol, Z. Codolá, I. Garcia-Bosch, L. Gómez, J. J. Pla, M. Costas, Nat. Chem., 2011, 3, 807-813.

A. R. Parent, R. H. Crabtree, G. W. Brudvig, Chem. Soc. Rev., 2013, 42, 22472252.

D. G. H. Hetterscheid, J. N. H. Reek, Eur. J. Inorg. Chem. 2014, 742-749.

A. R. Parent, T. P. Brewster, W. De Wolf, R. H. Crabtree, G. W. Brudvig, Inorg. Chem., 2012, 51, 6147-6152.

28

I. J. Davidson, J. E. Greedan, J. Solid State Chem., 1984, 51, 104-117.

29

A. Mills, T. Russell, J. Chem. Soc. Faraday Trans., 1991, 87, 1245-1250.

30 A. Mills, G. Meadows, Carbon, 1993, 31, 675-683.

31 R. J. Gledhill, D. B. Julian, J. Opt. Soc. Am., 1963, 53, 239-246.

32

A. Mills, G. Meadows, J. Chem. Soc., Faraday Trans., 1993, 89, 3849-3850.

33

A. Mills, H. Davies, J. Chem. Soc., Faraday Trans., 1991, 87, 473-478.

34

A. Mills, C. Lawrence, R. Enos, J. Chem. Soc., Chem. Commun., 1984, 21, 1436-1438.

35 A. Mills, N. McMurray, J. Chem. Soc., Faraday Trans., 1989, 85, 2055-2070.

36 G. F. Smith, C. A. Getz, Ind. Eng. Chem., Anal. Ed., 1938, 10, 191-195.

37 A. Henglein, J. Phys. Chem., 83, 1979, 2209-2216.

38 J. Kiwi, M. Grätzel, Chimia, 1979, 33, 289-291.

39 N. N. Greenwood, A. Earnshaw, Chemistry of the Elements, Pergamon Press, Oxford, 1984, ch. 17, pp. 1022-1026.

40 C. Vanleugenhaghe, G. Valesi, M. Pourbaix, in Atlas of Electrochemical Equilibria in Aqueous Solutions, ed. M. Pourbaix, Pergamon Press, Oxford, 1966, ch. 4, pp. 614-626.

41 G. J. Buist, W. C. P. Hipperson, J. D. Lewis, J. Chem. Soc. A, 1969, 307-312.

Tables 
Table 1 First order rate constants calculated over 1 half-life for the cerium system, and 2 half-lives for the periodate system.

\begin{tabular}{|c|c|c|c|c|c|}
\hline & Injection & $\mathrm{k} / \mathrm{min}^{-1}$ & $t_{1 / 2} / \min ^{-1}$ & $r^{2}$ & $\begin{array}{c}\Delta \text { Abs }_{800} \dagger \\
\text { (before injection) }\end{array}$ \\
\hline \multicolumn{6}{|c|}{ Cerium System (over 1 half-life) } \\
\hline \multirow[t]{3}{*}{$0.5 \mathrm{M} \mathrm{H}_{2} \mathrm{SO}_{4}$} & 1 & 0.326 & 2.13 & 0.9938 & 0.116 \\
\hline & 2 & 0.131 & 5.29 & 0.9874 & 0.0968 \\
\hline & 3 & 0.0589 & 11.8 & 0.9884 & 0.0785 \\
\hline \multicolumn{6}{|c|}{ Periodate System (over 2 half-lives) } \\
\hline \multirow[t]{3}{*}{$0.5 \mathrm{M} \mathrm{H}_{2} \mathrm{SO}_{4}$} & 1 & 0.0938 & 7.39 & 0.9965 & 0.126 \\
\hline & 2 & 0.0919 & 7.54 & 0.9985 & 0.144 \\
\hline & 3 & 0.0781 & 8.87 & 0.9992 & 0.162 \\
\hline \multirow[t]{3}{*}{ Water } & 1 & 0.489 & 1.42 & 0.9999 & 0.140 \\
\hline & 2 & 0.354 & 1.96 & 0.9998 & 0.258 \\
\hline & 3 & 0.296 & 2.34 & 0.9999 & 0.315 \\
\hline \multirow[t]{3}{*}{$0.1 \mathrm{M} \mathrm{KOH}$} & 1 & 0.0205 & 33.9 & 0.9880 & 0.209 \\
\hline & 2 & 0.0212 & 32.8 & 0.9962 & 0.138 \\
\hline & 3 & 0.0198 & 35.1 & 0.9981 & 0.137 \\
\hline
\end{tabular}

$\dagger \overline{A b S 800}$ (quartz cuvette + water) $=0.0442$ 


\section{Figure Captions}

(1) Schematic illustration of the electron transfer processes associated with the oxidation of water by an oxidant, Ox, mediated by a particle of a WOC.

(2) XRD of Ru(Adams) (blue line) recorded using a PANalytical X-ray powder diffractometer. The solid black lines represent the relative peak intensities of rutile phase $\mathrm{RuO}_{2}$ obtained from the Inorganic Crystal Structure Database (ICSD $\# 108861)^{28}$.

(3) UV/Vis absorption spectral changes, recorded every $1 \mathrm{~min}$, as a function of time after injection of $90 \mu \mathrm{L}$ of $0.1 \mathrm{M} \mathrm{Ce}(\mathrm{IV})$ solution into stirred $2.5 \mathrm{~mL}$ dispersion of $\mathrm{Ru}$ (Adams) $\left(60 \mathrm{mg} \mathrm{L}^{-1}\right)$ in $0.5 \mathrm{M} \mathrm{H}_{2} \mathrm{SO}_{4}$ contained in a $1 \mathrm{~cm}$ cuvette; the red vertical broken line highlights the wavelength used to monitor the kinetics of [Ce(IV)] decay, i.e. $430 \mathrm{~nm}$. The insert diagram illustrates the observed decays in absorbance, monitored at $430 \mathrm{~nm}$, of the same system as a function of time for 3 serial injections of $90 \mu \mathrm{L}$ of $0.1 \mathrm{M} \mathrm{Ce}(\mathrm{IV})$ solution into the $1 \mathrm{~cm}$ cuvette containing the dispersion of $\mathrm{Ru}$ (Adams) in $0.5 \mathrm{M} \mathrm{HNO}_{3}$.

(4) Schematic illustration of the current-voltage curves associated with the coupling, via redox catalysis, of the irreversible oxidation of water (solid line) to (i) the reversible (Nernstian) cathodic reduction of $\mathrm{Ce}$ (IV) (solid line) and (ii) the irreversible reduction of a different oxidant, $O x_{2}$ (broken line). Note in both cases the redox catalyst particles will adopt a mixture potential so that the rate of oxidation of the water (the anodic current) is equal to the rate of reduction of the oxidant, i.e. $\mathrm{Ce}(\mathrm{IV})$ or $\mathrm{Ox}_{2}$ (the cathodic current); both illustrated by broken vertical lines.

(5) Plot of the recorded change in pressure, as measured using the digital manometer in the system, following the injection (solid line) of a $2.5 \mathrm{~mL}$ dispersion of $10 \mathrm{mg}$ of $\mathrm{Ru}$ (Adams) into $100 \mathrm{~mL}$ of a $3.6 \mathrm{mM} \mathrm{Ce}(\mathrm{IV})$ solution in $0.5 \mathrm{M} \mathrm{H}_{2} \mathrm{SO}_{4}$; total change in pressure $=26.2 \mathrm{mbar}$. The broken line illustrates the change in pressure versus time recorded under the same conditions as above, i.e. under acidic conditions, but using $\mathrm{NaIO}_{4}$ as the oxidant; total change in pressure $=56.5$ mbar .

(6) UV/Vis absorption spectral changes, recorded every $1 \mathrm{~min}$, as a function of time after injection of $90 \mu \mathrm{L}$ of $0.1 \mathrm{M} \mathrm{NalO}_{4}$ solution into a stirred $2.5 \mathrm{~mL}$ dispersion of $\mathrm{Ru}$ (Adams), $60 \mathrm{mg} \mathrm{L}^{-1}$, in $0.5 \mathrm{M} \mathrm{H}_{2} \mathrm{SO}_{4}$ contained in a $1 \mathrm{~cm}$ cuvette; the red vertical 
broken line highlights the wavelength used to monitor the kinetics of $\left[\mathrm{H}_{5} \mathrm{IO}_{6}\right]$ decay, i.e. $280 \mathrm{~nm}$. The insert diagram illustrates the observed decays in absorbance, monitored at $280 \mathrm{~nm}$, of the same system as a function of time for 3 serial injections of $90 \mu \mathrm{L}$ of $0.1 \mathrm{M} \mathrm{NalO}_{4}$ solution into the $1 \mathrm{~cm}$ cuvette containing the dispersion of $\mathrm{Ru}$ (Adams) in $0.5 \mathrm{M} \mathrm{H}_{2} \mathrm{SO}_{4}$.

(7) Absorbance (measured at $280 \mathrm{~nm}$ ) versus decay time for 3 repeat injections of 90 $\mu \mathrm{L} 0.1 \mathrm{M} \mathrm{NaIO}_{4}$ into a $1 \mathrm{~cm}$ quartz cuvette containing a $2.5 \mathrm{~mL}$ dispersion of Ru-Adams (60 $\mathrm{mg} \mathrm{L}^{-1}$ ) in (a) water, and (b) $0.1 \mathrm{M} \mathrm{KOH}$. 


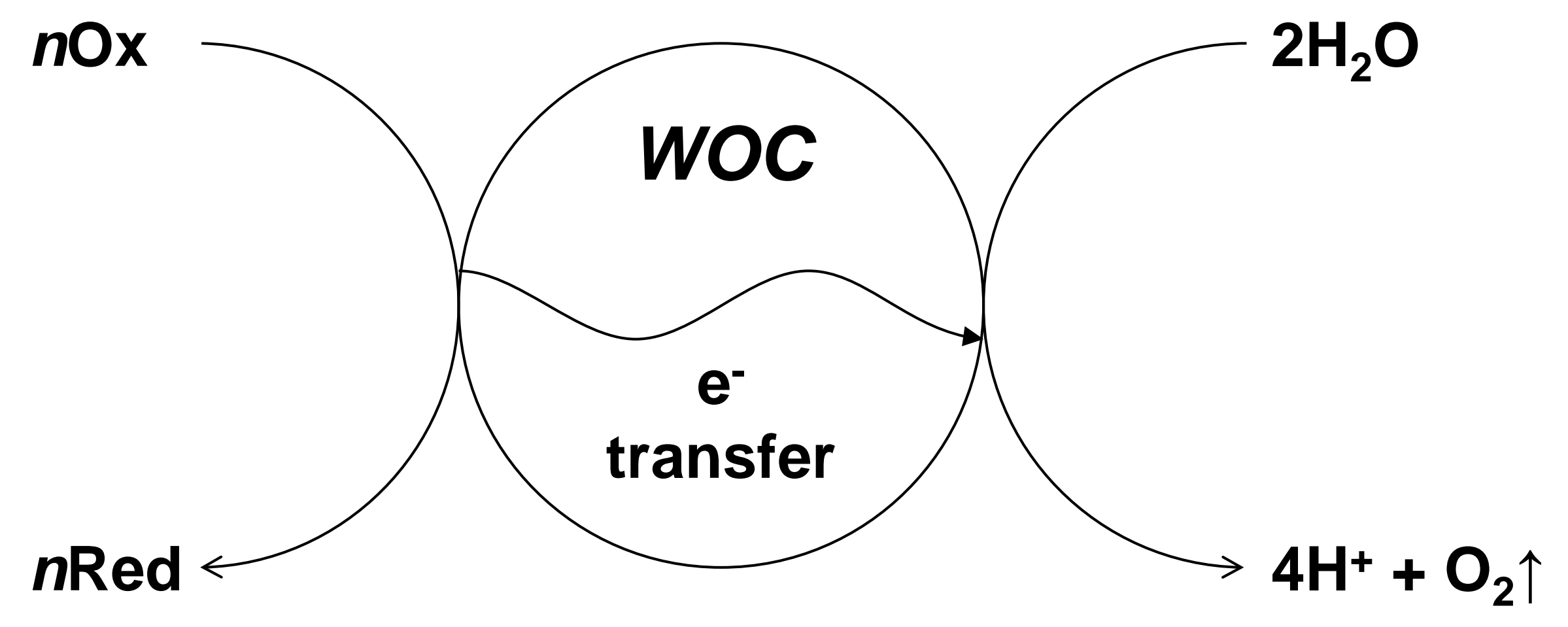

Figure 1 


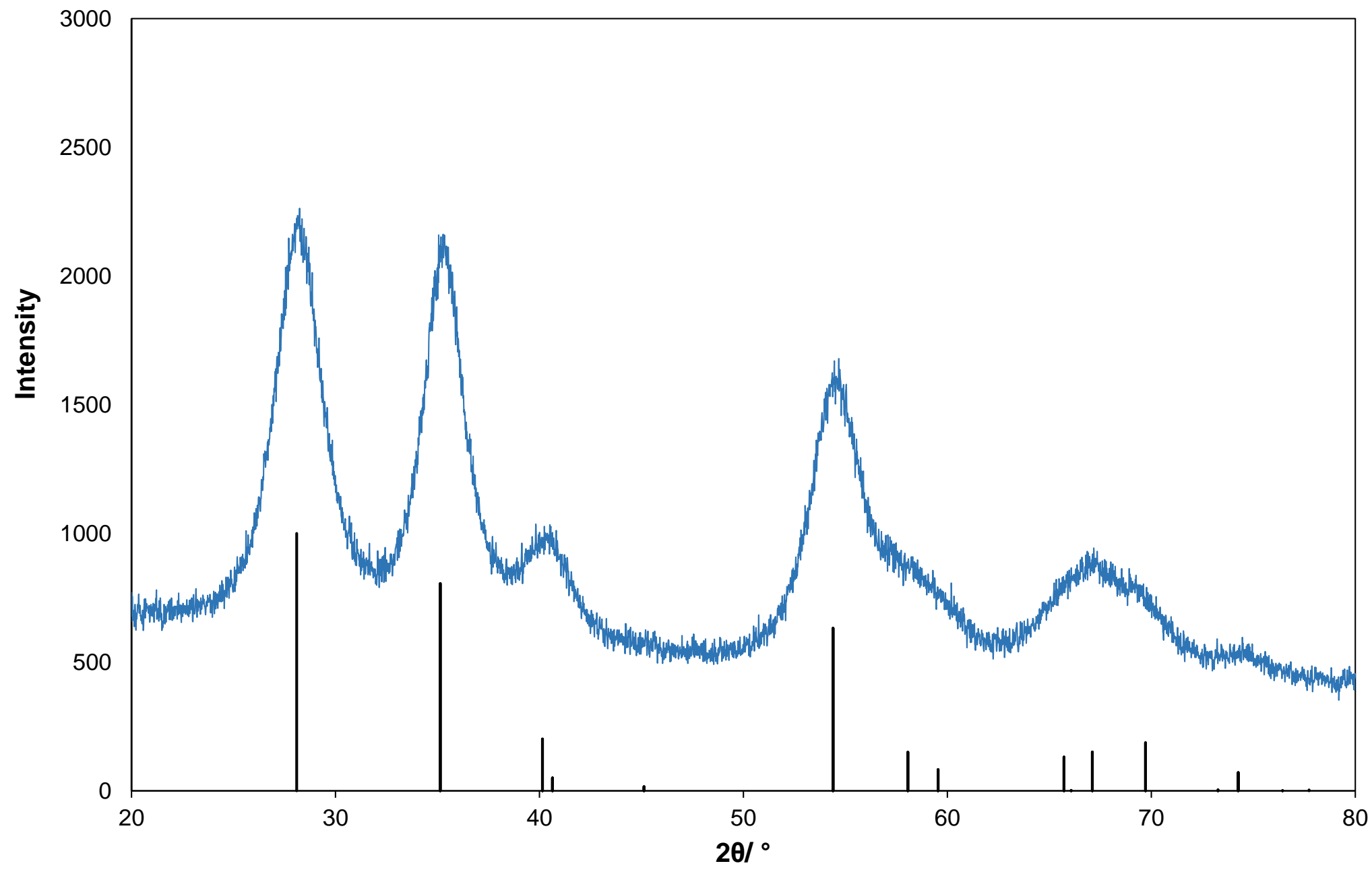

Figure 2 


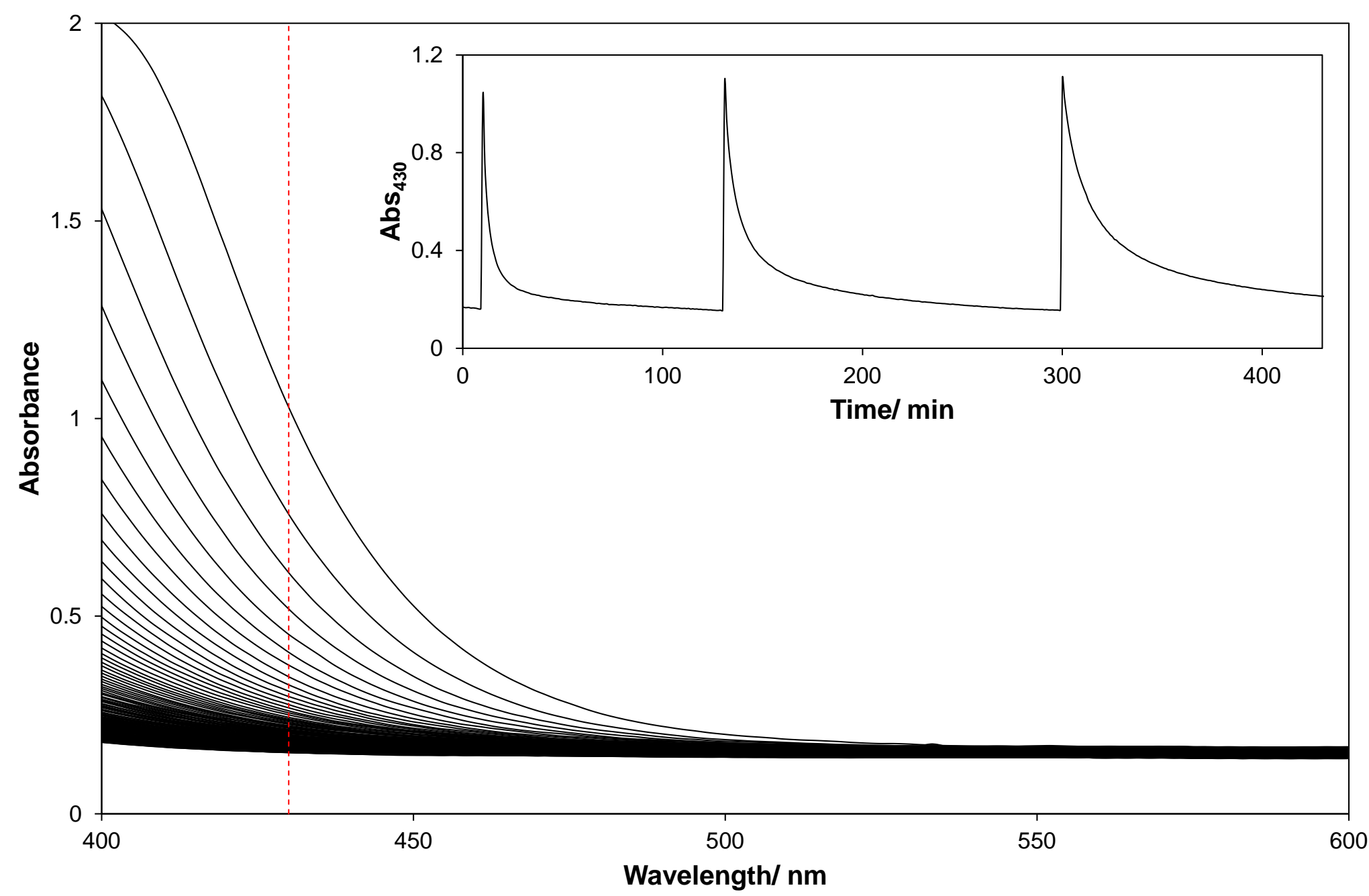

Figure 3 


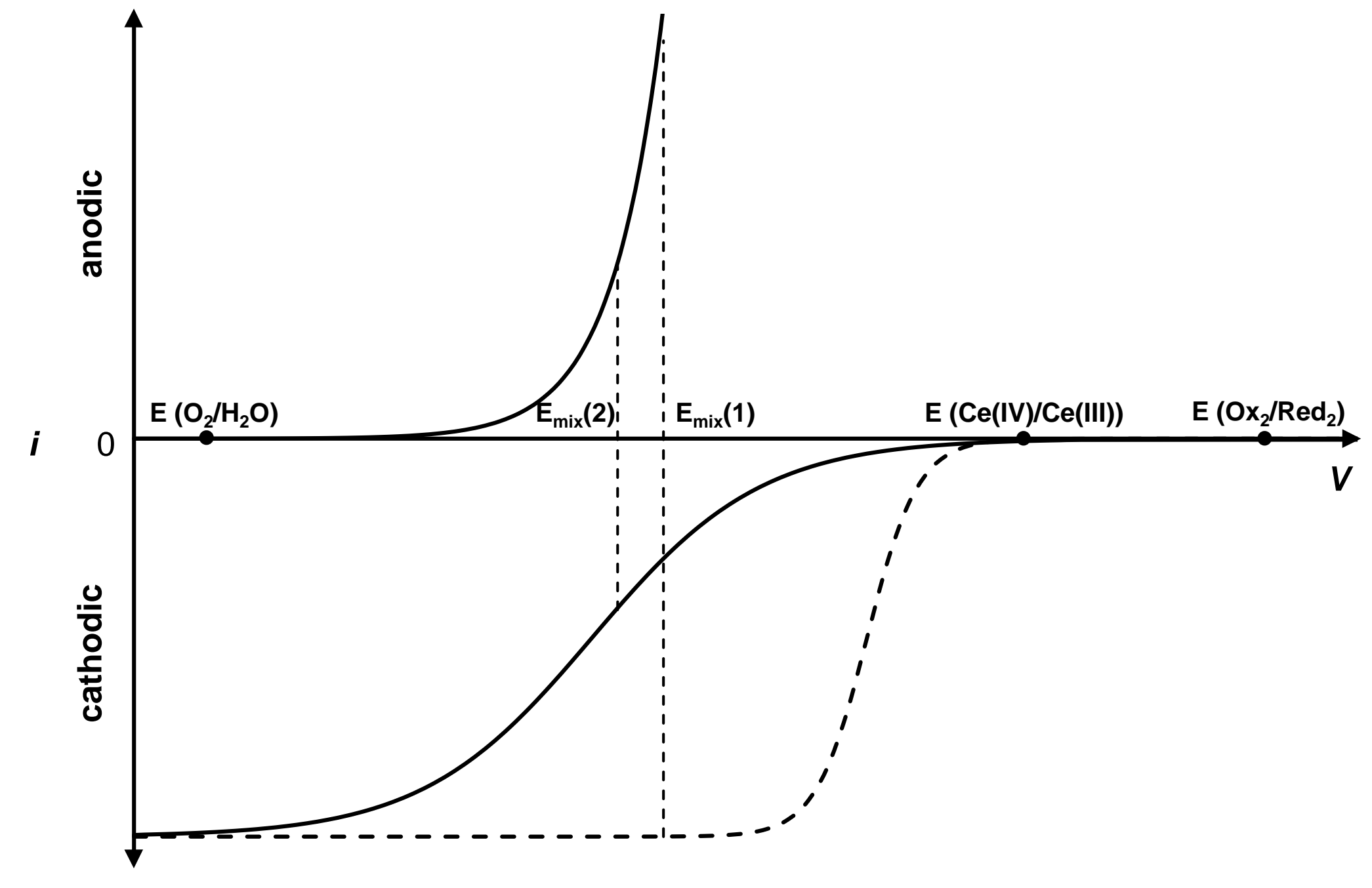

Figure 4 


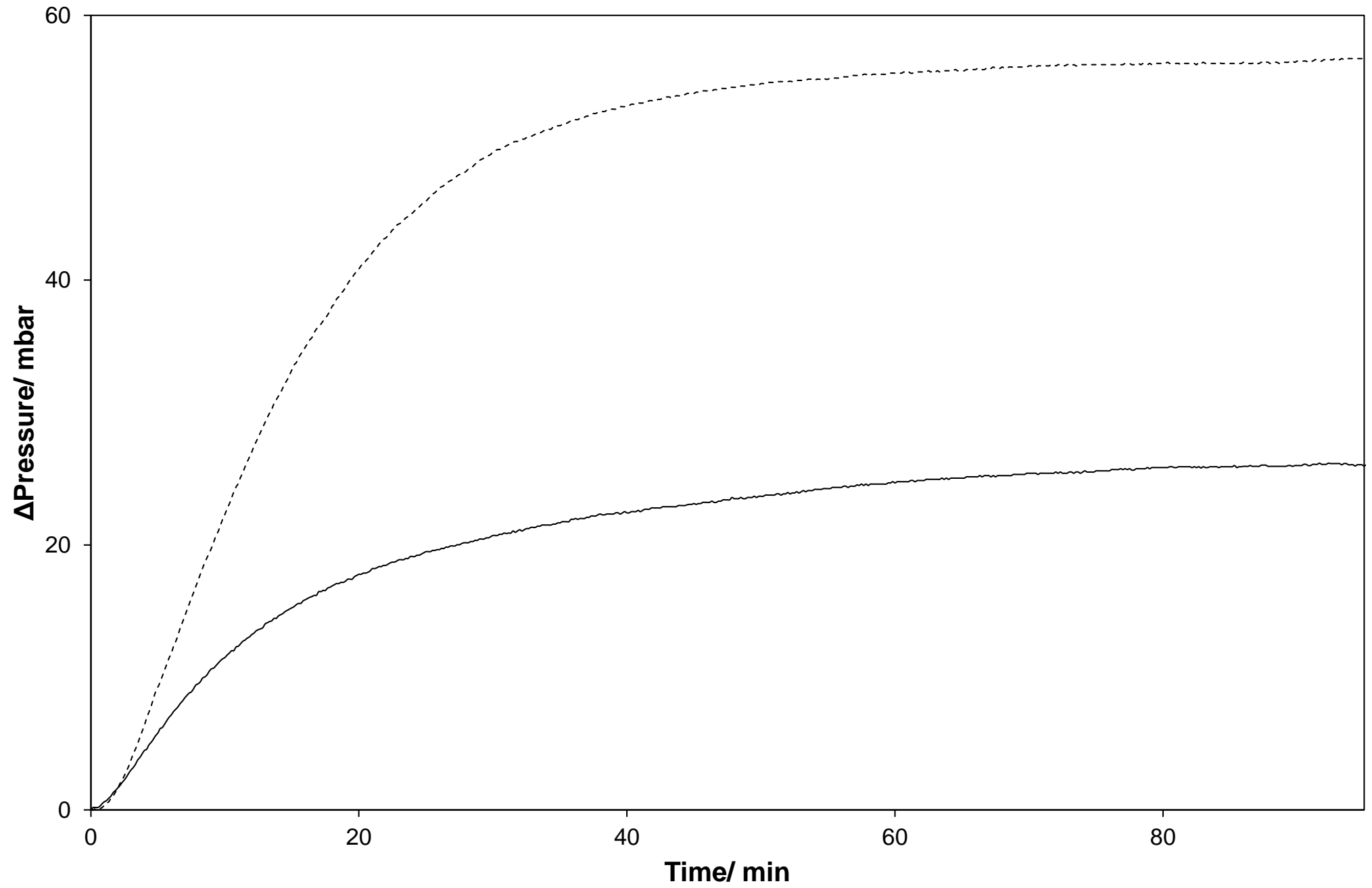

Figure 5 


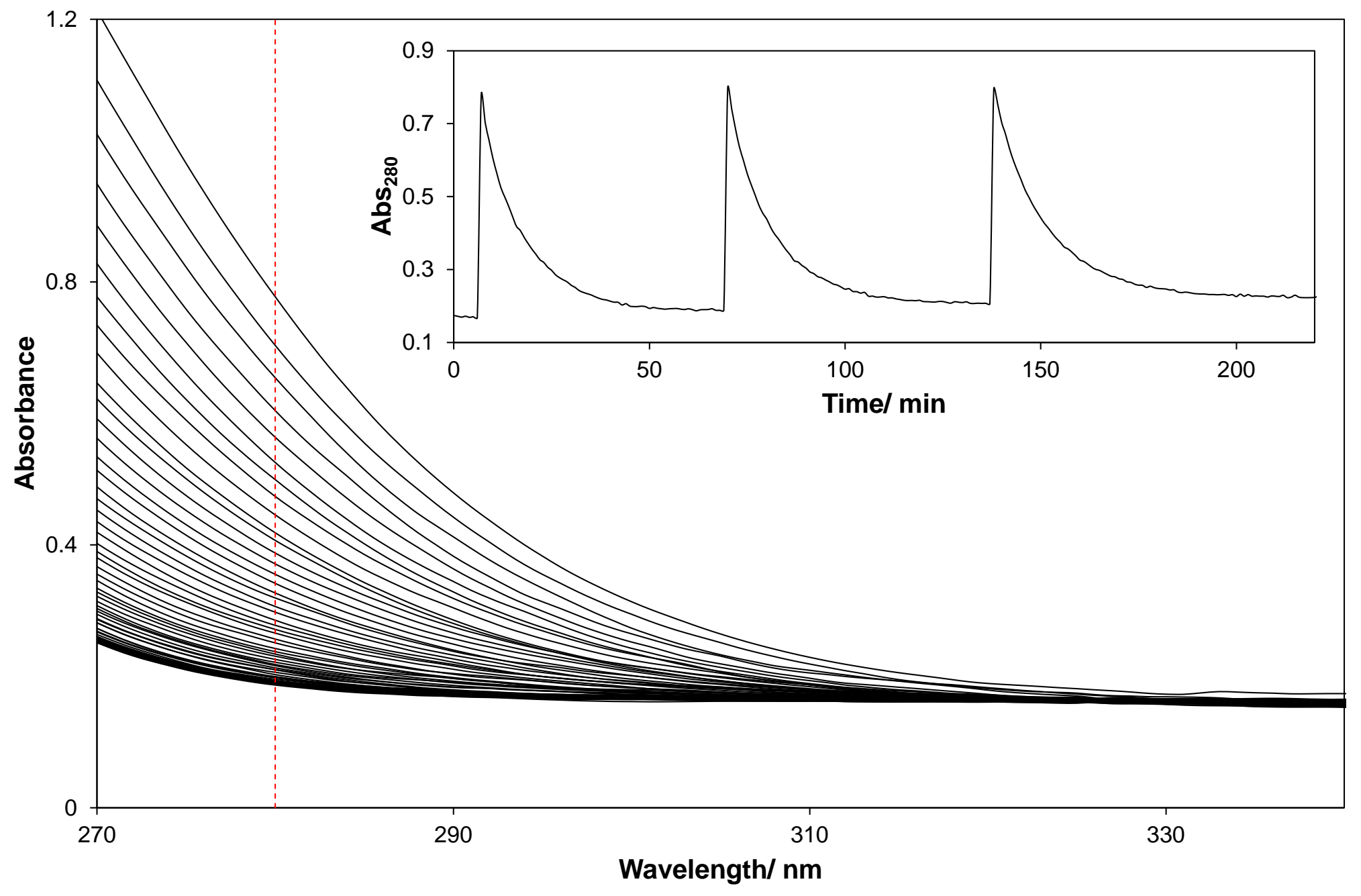

Figure 6 


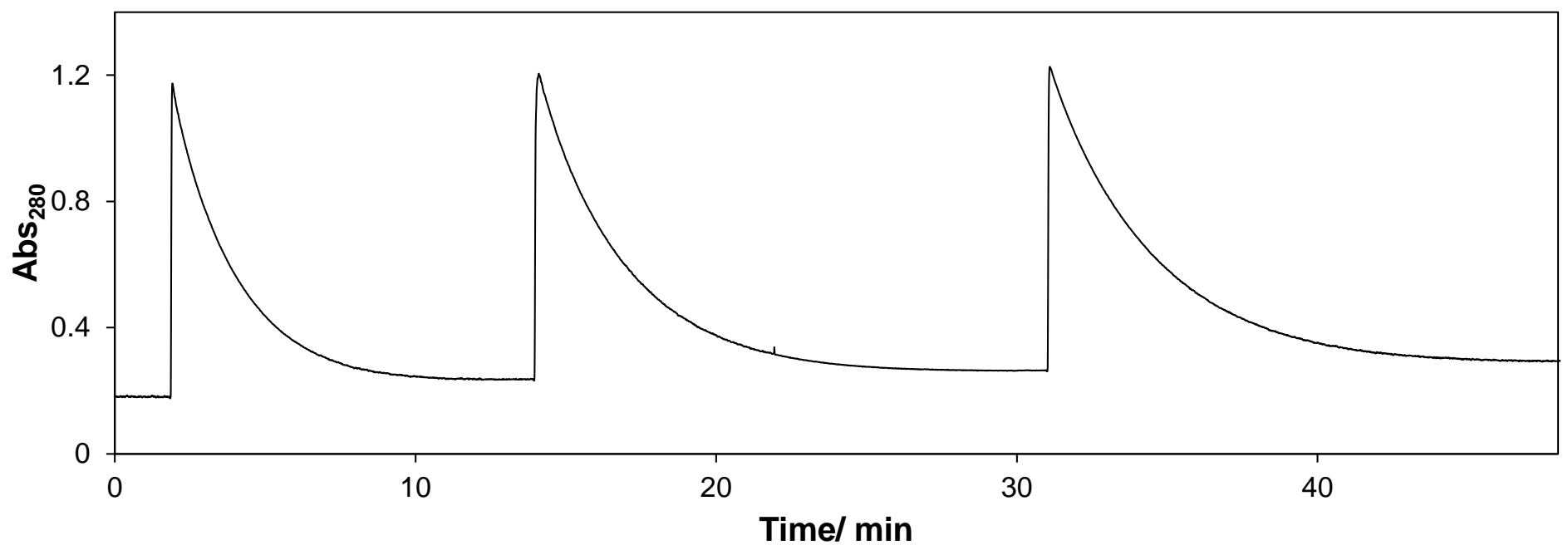

(a)

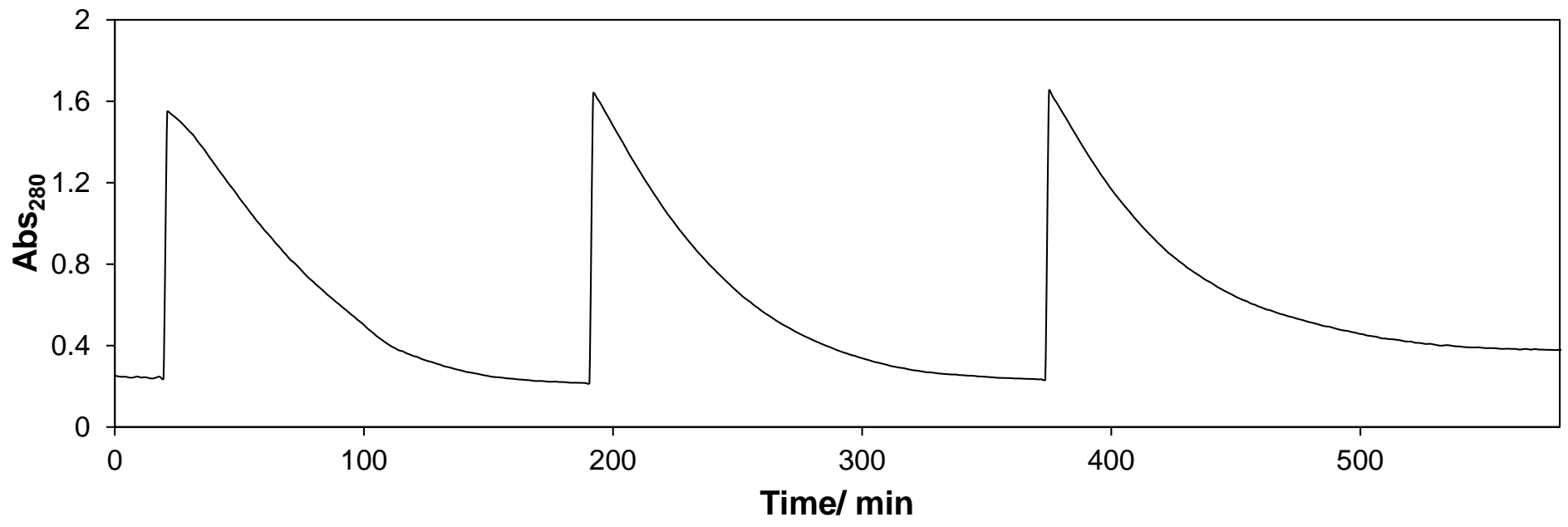

(b)

Figure 7 